\title{
Surrogate marker for predicting the virus binding of urogenital cancer cells during adenovirus-based gene therapy
}

\author{
Yun-Jun Lai, Rey-Chen Pong, John D. McConnell, and Jer-Tsong Hsieh
}

BioTechniques 35:186-194 (July 2003)

\begin{abstract}
Virus uptake is the first rate-limiting step for the successful gene delivery of any virus-based gene therapy. For adenovirus-based gene therapy, the expression levels of the adenovirus receptor-coxsackievirus and adenovirus receptor (CAR)—play an important role in dictating gene delivery. We have observed a wide spectrum of CAR expression among cancer cell lines and tumor specimens. Therefore, the screening of the CAR expression level in patients becomes crucial for any possible positive outcome. In this paper, we establish a real-time RT-PCR assay for the detection of CAR $m R N A$ levels from cancer cells and tumor specimens. This assay appears to be very quantitative, with sample concentrations ranging within 6 logs, and the sensitivity of this assay could detect as low as $1.8 \times 10^{2}$ copies of CAR cDNA per reaction. The results from this assay confirmed that there was a good linear relationship between the CAR mRNA and virus binding from each cell line. With this assay, we were able to detect changes in CAR gene expression in cells treated with histone deacetylase inhibitor. Most importantly, CAR $m R N A$ levels directly correlated with its protein levels prepared from tumor specimens. Taken together, this assay could provide a rapid screening tool for any adenovirus-based gene therapy trial.
\end{abstract}

\section{INTRODUCTION}

Adenovirus entry into target cells is mediated by a specific receptor $(1,2)$. The coxsackievirus and adenovirus receptor (CAR) protein has been demonstrated as a high-affinity receptor for adenovirus type $5(3,4)$, and the presence of this protein significantly enhances the efficiency of adenoviral vector-mediated gene transfer $(4,5)$. CAR is a 46-kDa transmembrane glycoprotein that contains intracellular, transmembrane, and extracellular domains with two immunoglobulin-like motifs that interact with the knob protein from the adenovirus type 5 (4). Although many other studies indicate that several other molecules, such as integrin and heparan sulfate proteoglycan, could influence virus uptake $(6-10)$, the levels of the CAR protein appear to be a key determinant for dictating the virus sensitivity in urogenital cancer $(5,11)$. Our recent studies and others showed that there is a wide spectrum of CAR expression among different cancer cell lines and clinical specimens. Therefore, determining the CAR levels in target cells becomes critical to the selection of patients who may be good candidates for any adenovirus-based gene therapy trial.

To detect the expression of CAR, various methods have been reported $(5,12)$. Nevertheless, these methods do not appear to be very quantitative. In this study, we decided to explore a quantitative real-time RT-PCR assay to detect CAR gene expression. The standard curve of the assay demonstrates that it can detect sample concentrations ranging within a 6-log scale. The sensitivity of this assay could even reach as low as 200 molecules of CAR cDNA in any given sample. With this assay, we correlated the expression levels of CAR mRNA with virus binding from a variety of cell lines. In addition, we also observed a good linear relationship between the steady-state levels of CAR mRNA and protein obtained from tumor specimens. Based on these results, we believe that real-time RT-PCR for CAR mRNA could offer a sensitive, quantitative, and swift assay for future preclinical and clinical trials.

\section{MATERIALS AND METHODS}

Cell Culture, Tumor Specimens, and RNA Isolation

Prostate cell lines were maintained in the media as previously described (13). Bladder cell lines were obtained from ATCC (Manassas, VA, USA) and were maintained in T-medium containing 5\% fetal bovine serum (FBS) (5). These cells were routinely cultured in a humidified incubator at $37^{\circ} \mathrm{C}$ with $5 \% \mathrm{CO}_{2}$.

To induce human tumor in an athymic mouse, $1 \times 10^{6}$ cells per site were subcutaneously injected into the flanks of 8- to 10-week-old male hosts (one injection/animal; two animals for 253J-RFV, three animals for T24, two animals for DU145, and three animals 
for PC-3). Once the tumors became palpable (after 4 weeks of inoculation), the palpable growth of subcutaneous tumors was measured weekly with a caliper, and the tumor volume was calculated (volume $=$ length $\times$ width $\times$ height $\times 0.5236$ ). Eight weeks after inoculation, tumor specimens about 100 $\mathrm{mm}^{3}$ in size were excised from the host and snap-frozen at $-80^{\circ} \mathrm{C}$ until use. For clinical specimens, the samples were retrieved from the tissue bank from our department; the tissue procurement protocol was approved by the Institutional Review Board (IRB) committee, and informed consent was obtained from all patients.

Total RNA was isolated from cultured cells with $60 \%$ to $80 \%$ confluency using RNA-Bee ${ }^{\circledR}$ reagent (Tel-Test, Houston, TX, USA) according to the manufacturer's protocol. For the tumor-tissue RNA extraction, approximately $50 \mathrm{mg}$ tissue from each sample were used in the protocol.

\section{Real-Time RT-PCR Assay}

To establish a standard curve of realtime PCR, we used pTOPOCAR (5) and pTOPOGAPDH. The primer set used to detect CAR cDNA was CAR3, 5'-GCCTTCAGGTGCGAGATGTTAC- $3^{\prime}$ and CAR4, 5'-GAACACGGAGAGCACAGATGAGAC-3', and the expected size of the PCR product (nucleotides 479-1192; GenBank ${ }^{\circledR}$ accession no. NM 001338) was 714 bp. The primer set used to detect GAPDH cDNA was G3P4, 5'-AGTGAGCTTCCCGTTCAAC- ${ }^{\prime}$ and G3P7, 5'-GAAGGTGAAGGTCGGAGTCAACG-3',

and the expected size of PCR product (nucleotides 109-790; no. AF261085) was $682 \mathrm{bp}$. A $40-\mu \mathrm{L}$ reaction mixture contained SYBR ${ }^{\circledR}$ Green $(1: 10,000$; Cambrex, Rockland, ME, USA), 1× Platinum ${ }^{\circledR}$ Quantitative PCR SuperMix-uracil-DNA glycosylase (UDG) (Invitrogen, Carlsbad, CA, USA), which consists of $30 \mathrm{U} / \mathrm{mL}$ Platinum Taq DNA polymerase, $20 \mathrm{mM}$ Tris$\mathrm{HCl}, \mathrm{pH} 8.4,50 \mathrm{mM} \mathrm{KCl}, 3 \mathrm{mM}$ $\mathrm{MgCl}_{2}, 200 \mu \mathrm{M}$ dATP, dCTP, dGTP, $400 \mu \mathrm{M}$ dUTP, $20 \mathrm{U} / \mathrm{mL}$ UDG, and stablizers. The reaction was carried out at $95^{\circ} \mathrm{C}$ for $2 \mathrm{~min}$, and then followed by 35 cycles of $92^{\circ} \mathrm{C}$ for $15 \mathrm{~s}, 57^{\circ} \mathrm{C}$ for 30 $\mathrm{s}$, and $72^{\circ} \mathrm{C}$ for 1.5 min using an iCycler $^{\circledR}$ thermal cycler (Bio-Rad Laboratories, Hercules, CA, USA). To measure the melting curve, the proto$\operatorname{col}\left(95^{\circ} \mathrm{C}\right.$ for $1 \mathrm{~min}$ and $55^{\circ} \mathrm{C}$ for 1 min, with an increment of $0.5^{\circ} \mathrm{C} /$ cycle for 80 cycles) was carried out.

For RT-PCR, an equal amount of total RNA ( $2 \mu \mathrm{g}$ for culture cells and $3.2 \mu \mathrm{g}$ for tumor tissue) was reverse-transcribed to firststrand cDNA synthesis using SUPERSCRIPT TM II (Invitrogen) with $100 \mathrm{ng}$ random hexamer, and then $2.5 \mu \mathrm{L}$ first-strand cDNA were subjected to real-time PCR. The relative CAR mRNA level was determined by normalizing the copy number of the CAR cDNA with the copy number of the GAPDH cDNA from each sample.

\section{Western Blot Analysis}

Cell lysate was prepared by the addition of lysis buffer containing $1 \%$ Triton $^{\circledR}$ X-100 and $10 \%$ glycerol (14). The lysate was stored at $-80^{\circ} \mathrm{C}$ overnight, and then the supernatant was collected by centrifugation at 12,000 rpm for $1 \mathrm{~min}$ at $4^{\circ} \mathrm{C}$. The protein concentration of each sample was determined using the Bradford method (Bio-Rad Laboratories). An equal amount of protein from each sample was loaded onto a $10 \%$ SDS-polyacrylamide gel and electrotransferred to a nitrocellulose membrane. After blocking with phosphate-buffered saline with Tween ${ }^{\circledR} 20$ (PBST) contain-

Figure 1. Quantitation of CAR mRNA levels among different human cancer cells. (A) The standard curve of real-time PCR. (B) The relative CAR mRNA level among cancer cells after normalization with GAPDH mRNA. Data $(\overline{\mathrm{x}} \pm \mathrm{SD})$ were calculated from experiments performed in triplicate. TCC, transitional cell carcinoma. 
ing $5 \%$ powdered milk, the membrane was incubated with anti-ADR antibody (1:500) (15) for $2 \mathrm{~h}$, followed by incubation with a horseradish peroxidase (HRP)-conjugated goat anti-rabbit immunoglobulin $\mathrm{G}(\mathrm{IgG})$. After an extensive washing, the protein was visualized using a SuperSignal ${ }^{\circledR}$ West Dura Extended Duration Substrate (Pierce Chemical, Rockford, IL, USA). Intelligent Quantifier® software (BioImage, Ann Arbor, MI, USA) was used to quantify the intensity of each protein band. To determine the relative CAR protein levels, the intensity of the CAR protein band was normalized with the intensity of the actin protein band from each sample.

\section{Virus Receptor Binding Assay}

$\left[{ }^{3} \mathrm{H}\right]$-thymidine-labeled d1312 adenovirus $\left(1 \times 10^{6} \mathrm{pfu}\right.$; specific activity, $2.4 \times 10^{-3} \mathrm{cpm} / \mathrm{pfu}$ ), purified by two cycles of $\mathrm{CsCl}$ gradient ultracentrifugation (5), was incubated with $5 \times 10^{5}$ cells suspended in $1 \mathrm{~mL}$ PBS at $4^{\circ} \mathrm{C}$ for $1 \mathrm{~h}$. The cell suspension was then loaded onto $3 \mathrm{~mL}$ PBS buffer gradient containing $2 \%$ bovine serum albumin (BSA) and $10 \%$ sucrose and centrifuged in a swinging bucket rotor at $2000 \mathrm{rpm}$ for $5 \mathrm{~min}$ (3). The cell pellet was lysed in $0.3 \mathrm{M} \mathrm{NaOH}$ solution and then subjected to a liquid scintillation counter to determine the total amount of virus binding.

\section{Detection of Virus-Mediated Gene Delivery}

To determine the viral sensitivity of human cancer cells, $5 \times 10^{5}$ cells were infected with different concentrations of Ad-cytomegalovirus (CMV)- $\beta$-gal viruses at $37^{\circ} \mathrm{C}$ in a $5 \% \mathrm{CO}_{2}$-humidified incubator. We determined the virus-mediated gene delivery using a $\beta$ galactosidase assay that has been previously described (5).

\section{RESULTS}

\section{Quantification of CAR mRNA Using a Real-Time RT-PCR Assay}

Previously, we have demonstrated that CAR is the key receptor for aden- ovirus, and its expression levels vary widely among different urogenital cancer cells $(5,11)$. It is therefore critical to quantify the amount of CAR in any given target tissue during gene therapy. We decided to explore whether the levels of CAR mRNA can be correlated with CAR protein levels and virus binding in each cell. To test this hypothesis, we employed a real-time RTPCR assay. To establish the standard curve of the real-time PCR assay, a full-length CAR cDNA (i.e., pTOPO-
CAR) with concentrations ranging from $10^{-3}$ to $10^{-9} \mu \mathrm{g}\left(1.8 \times 10^{2}\right.$ to $1.8 \times$ $10^{8}$ copies) was subjected to a $40-\mu \mathrm{L}$ PCR. By plotting the threshold cycle $\left(C_{t}\right)$ value with the copy number of CAR cDNA, the standard curve with a regression coefficient $(\mathrm{R})$ of 0.997 was determined (Figure 1A). Based on this curve, we concluded that the sensitivity of this assay ranges from approximately 200 to 200 million copies (i.e., 6 logs) of CAR cDNA. On the other hand, the regression coefficient of the

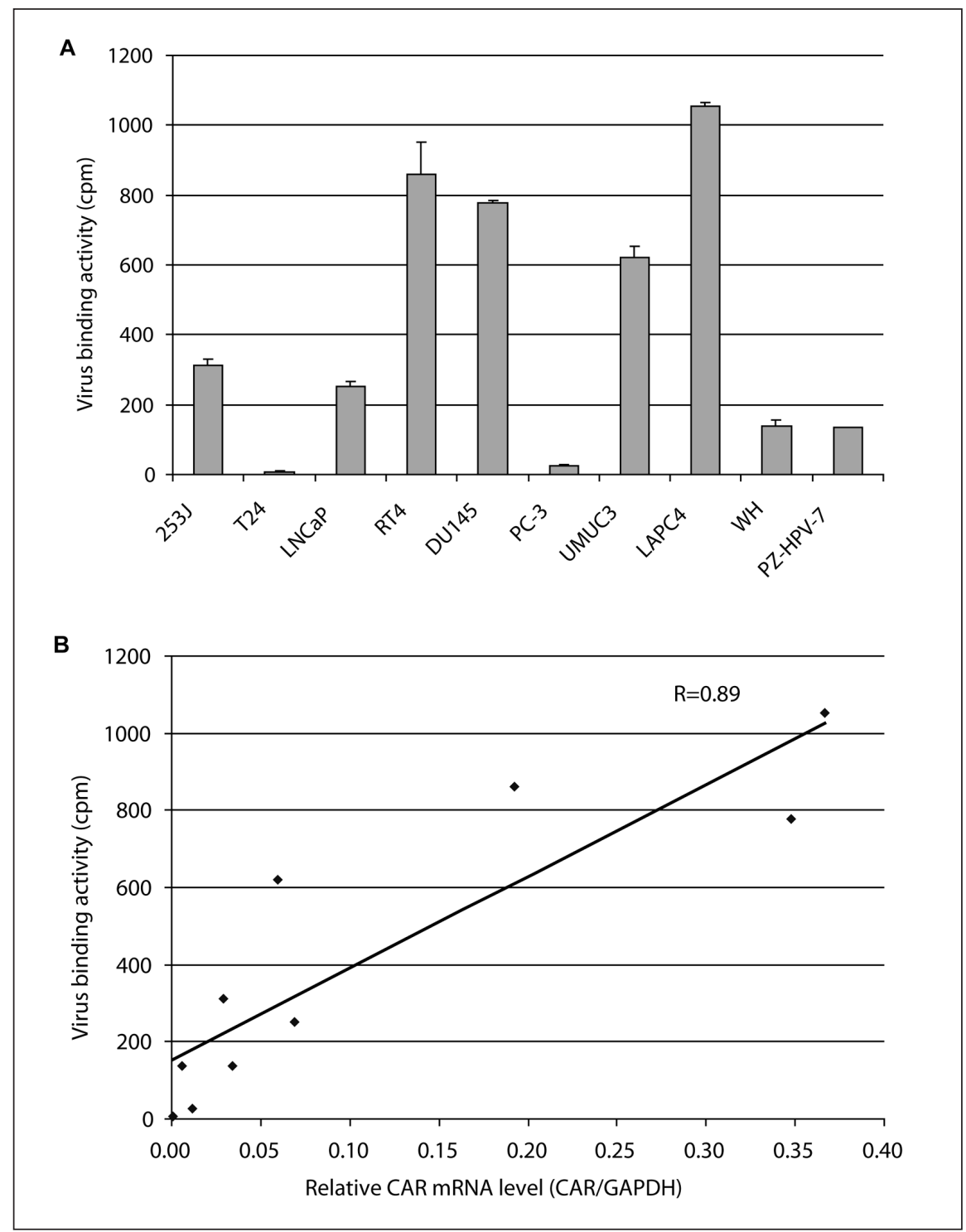

Figure 2. The correlation between the CAR mRNA level and the virus binding in prostate and bladder cell lines. One million plaque-forming units of $\left[{ }^{3} \mathrm{H}\right]$-thymidine-labled d1312 adenovirus were incubated with $5 \times 10^{5}$ cells for $1 \mathrm{~h}$. The binding of each cell was determined by scintillation counting. (A) Different virus binding among prostate and bladder cancer cell lines. (B) The correlation between the virus binding and the relative CAR mRNA level in prostate and bladder cancer cell lines. Data $(\overline{\mathrm{x}} \pm$ SD) were calculated from experiments performed in triplicate. 
GAPDH cDNA standard curve is 0.990, and the linear relationship ranges from 700 to 700 million copies (i.e., 6 logs) of GAPDH cDNA.

To measure CAR mRNA levels, 2 $\mu \mathrm{g}$ total cellular RNA were subjected to a real-time RT-PCR. To ensure the fidelity of the RT-PCR, we performed melting curve analysis, gel electrophoresis, and DNA sequencing to confirm only one single species of cDNA (data not shown). Using this assay, we compared the CAR mRNA levels from 18 different human prostate and bladder cells, including primary cells derived from normal tissue (i.e., PrEC, PZ-HPV-7, SWNPC1, and SWNPC2) and malignant tissue. As shown in Figure 1B, a wide spectrum of CAR mRNA expression was detected. In general, prostate cells have higher CAR mRNA levels than bladder cells. Among them, LAPC4, MDAPCa2a, DU145, and RT4 expressed the highest levels (more than $3 \times 10^{5}$ copies/ $\mu$ g RNA) and MDAPCa $2 b$, SWPC1, and SWNPC2 expressed an intermediate level (from $1.5 \times 10^{5}$ to 3 $\times 10^{5}$ copies/ $\mu$ g RNA), whereas the rest of the 10 cell lines expressed very low levels. Noticeably, the CAR mRNA in the T24 cell line appeared to be negative. We also normalized these data with an internal control GAPDH, and the expression profiles of CAR/ GAPDH for all the cell lines remained the same except for the LAPC4 cell line (Figure 1B), indicating that the real-time RT-PCR for CAR mRNA detection is highly reproducible.

\section{Correlation of CAR mRNA \\ Expression and Binding of \\ Adenovirus to Target Cells}

Although the real-time RT-PCR assay provides a sensitive assay to detect CAR mRNA, it is uncertain that the
CAR mRNA levels can reflect the virus binding of each given cell. We thus performed a virus binding assay using $\left[{ }^{3} \mathrm{H}\right]$-thymidine labeled adenovirus (5) from 10 different cell lines with the different CAR mRNA levels. As shown in Figure $2 \mathrm{~A}$, the overall virus binding assay correlated with the CAR mRNA from each cell line. After plotting virus binding with the CAR/GAPDH mRNA copy number, we got a positive linear curve with a regression coefficient of 0.89 (Figure 2B). Data from Figure 2B also suggested that the presence of components other than CAR on the cell membrane might interact with adenovirus with a low affinity because we noticed that there is a threshold of virus binding, while CAR mRNA was almost undetectable in the cells. Nevertheless, the real-time RT-PCR assay proves to be a valuable surrogate tool to determine the virus binding of target cells, and CAR appears to be the princi-

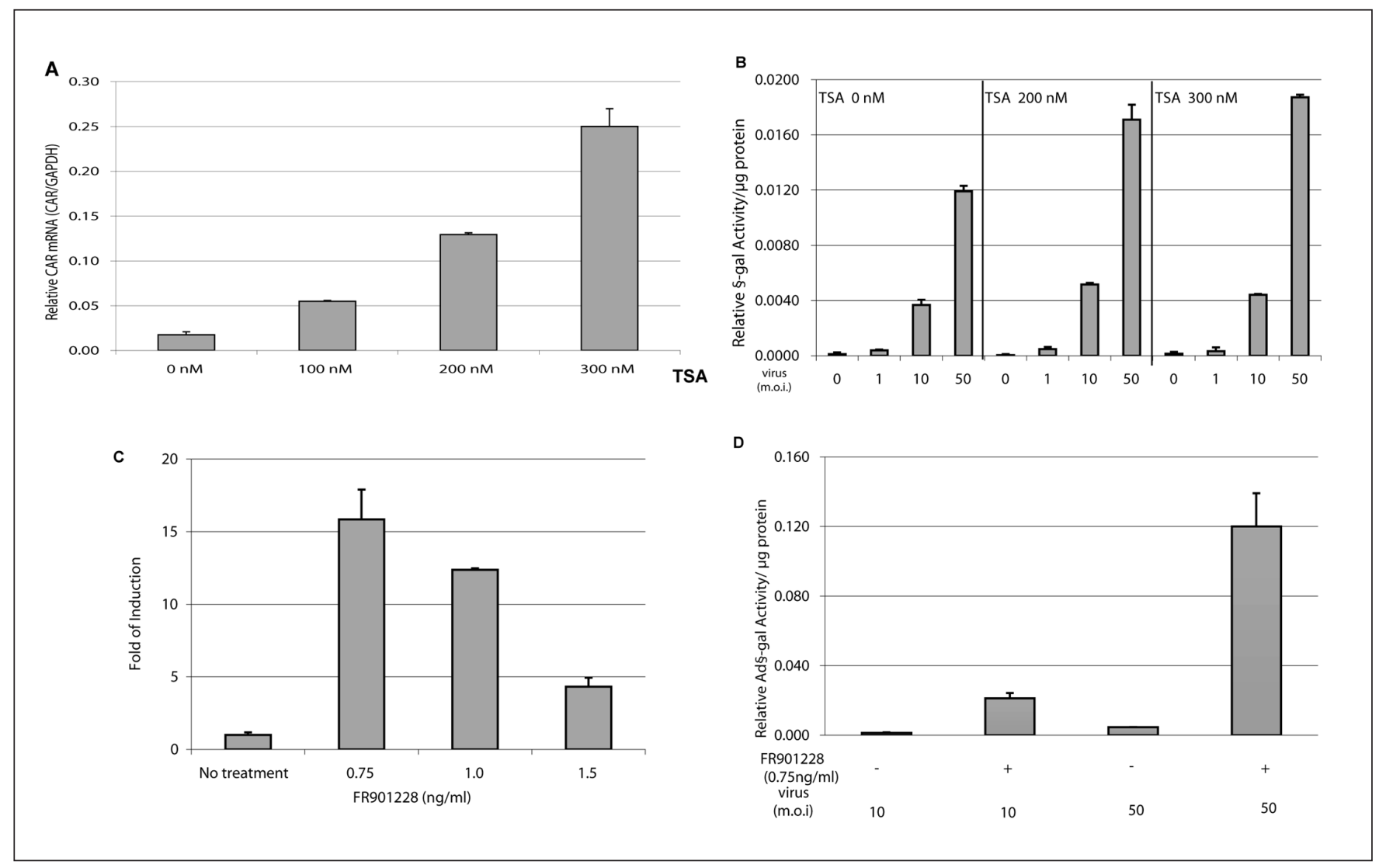

Figure 3. Increased CAR gene expression in urogenital cancer cells induced by HDAC inhibitors. PC-3 cells $\left(5 \times 10^{5}\right.$ cells/p 100 plate $)$ were treated with various concentrations of trichostatin A (TSA), and TCC cells $\left(5 \times 10^{5}\right.$ cells/p100 plate) were treated with various concentrations of FR901228. The cells were harvested 3 days after treatment. (A) The relative CAR mRNA levels in PC-3 cells treated with TSA. (B) increased virus sensitivity in PC-3 cells treated with TSA. (C) The relative CAR mRNA levels in TCC cells treated with FR901228. (D) Increased virus sensitivity in TCC cells treated with FR901228. Data ( $\bar{x} \pm$ SD) were calculated from experiments performed in triplicate. 
pal receptor to determine the virus binding in any given cell.

\section{Detection of Increased CAR Gene Expression Using a Real-Time RT-PCR Assay}

It is known that some cancer cells are resistant to virus infection due to the loss of CAR expression. Data from Figure $1 \mathrm{~B}$ indicated that decreased $\mathrm{CAR}$ mRNA expression is the major cause of this phenomenon. Several studies demonstrate that the expression of the endogenous CAR gene can be induced by histone deacetylase (HDAC) inhibitor (16-18). However, it has not been proven in urogenital cancer. Therefore, a PC-3 cell, a low CAR expresser, was treated with different dosages $(100,200$, and $300 \mathrm{nM})$ of trichostatin A (TSA), an HDAC inhibitor, for three days. We employed the realtime RT-PCR assay to detect the elevation of CAR mRNA levels because this assay is very sensitive. Figure $3 \mathrm{~A}$ shows that TSA could induce the steady-state levels of CAR mRNA in a dosage-dependent manner; the maximal induction is about 15 fold. Concurrently, the virus sensitivity was also elevated in PC-3 cells in the presence of TSA (Figure 3B). In contrast, an increased CAR expression was also detected in transitional cell carcinoma (TCC; bladder cancer) cells after treatment with FR901228, a HDAC inhibitor (18), for 3 days (Figure 3C). We further showed that the virus sensitivity of these cells was enhanced with this agent (Figure 3D). In general, when the TSA concentration was higher than $300 \mathrm{nM}$, it appeared to be more toxic than FR90228 in urogenital cancer cells.

\section{Detection of CAR Levels from In Vivo Tumor Specimen Using a Real-Time RT-PCR Assay}

Apparently, the CAR expression status is critical to the success of gene therapy using adenovirus vectors; therefore, the CAR level in tumor specimens becomes a potent screening marker for the selection of suitable patients and is a reference for adjusting virus administration schedule and dosage. We have collected tumors from animals injected with cancer cell lines expressing different levels of CAR (Figure 1B). Several individual tumor biopsies generated from each cell line were harvested; cell lysate and total cellular RNA prepared from the same tumor specimen were subjected to Western blot analysis and a real-time RTPCR assay, respectively. The result (Figure 4A) of the real-time RT-PCR using

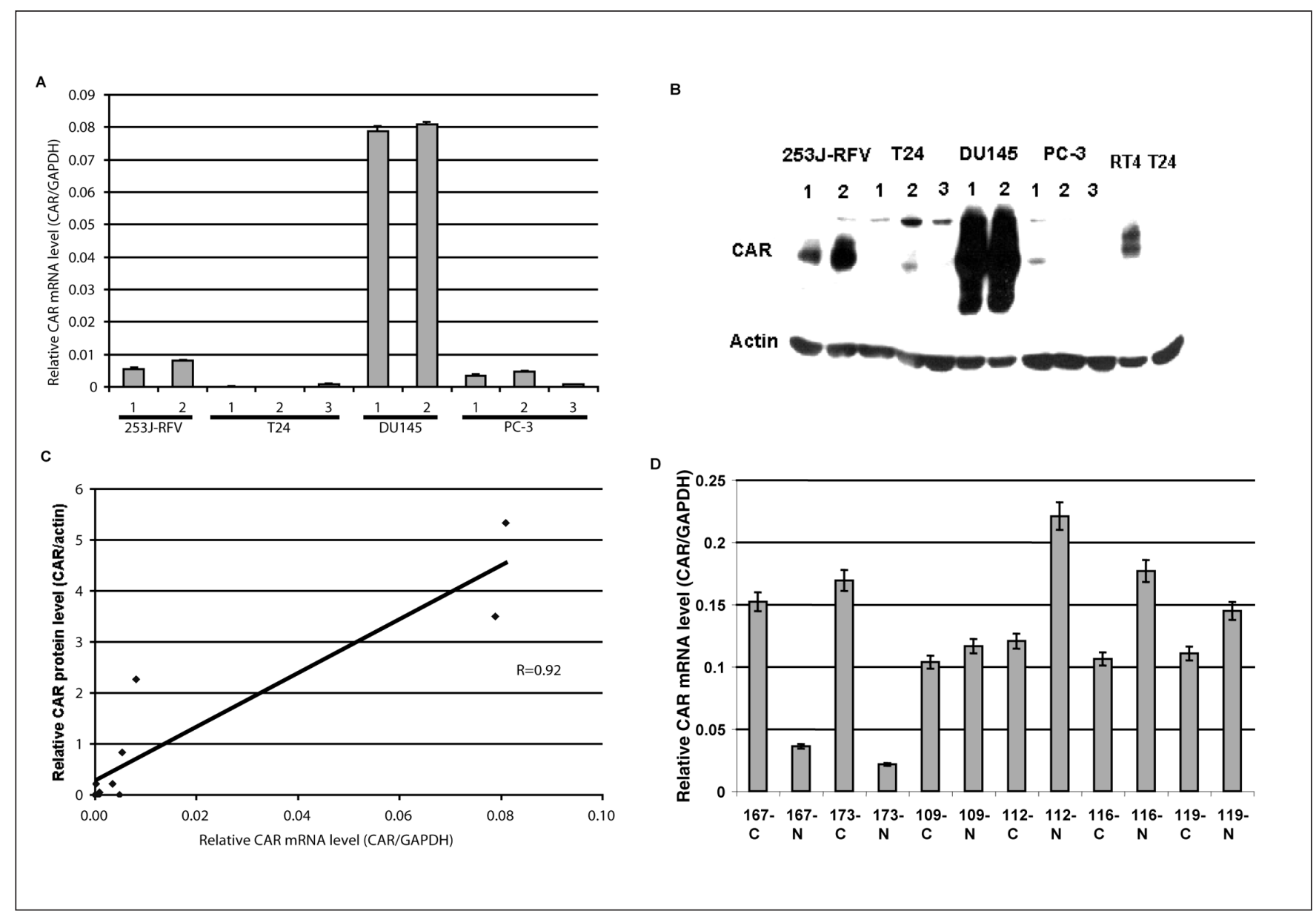

Figure 4. The application of real-time RT-PCR using tumor specimens. Total cellular RNA ( $3.2 \mu \mathrm{g})$ prepared from either tumor tissues from xenograft (A-C) or bladder cancer specimens derived from each individual (D) was subjected to a real-time RT-PCR, and $60 \mu \mathrm{g}$ cell lysate prepared from the same sample were subjected to Western blot analysis (B). The linear regression curve was plotted between the relative CAR protein level and mRNA level (C). N, normal; $\mathrm{C}$, cancer. Data $(\overline{\mathrm{x}} \pm \mathrm{SD})$ were calculated from experiments performed in triplicate. 
the total cellular RNA prepared from the same tumor biopsy demonstrated that DU145-induced tumors expressed the highest CAR mRNA compared to other cell lines (253J, T24, and PC-3) tested. Although each tumor may contain more than one cell type contributed by the host, the profile of CAR mRNA expression in these tumors was still consistent with the in vitro CAR mRNA levels of each cell line (Figure 1B). Data (Figure 4B) from Western blot analysis also indicated that the DU145-induced tumor expressed the highest amount of CAR protein among the four different kinds of cells tested. By plotting the relative CAR protein level (ratio of CAR/actin) with the relative CAR mRNA level (ratio of CAR/GAPDH), the majority of data points fell to both ends of the curve because the CAR levels from the available tumor specimens used in this study were not in the middle range. Nevertheless, we were still able to get a good linear relationship with a significant regression coefficient of 0.92 (Figure 4C). With the real-time RT-PCR, we also observed a heterogeneous expression of CAR mRNA from clinical specimens of bladder cancer patients (Figure 4D), which indicates that this assay has a potential clinical application.

\section{DISCUSSION}

Recombinant adenovirus has become a very popular vector in many clinical trials. We have documented a wide spectrum of CAR expression among different cancer cell lines and tumor specimens $(5,11,19,20)$. We have also documented that increased CAR expression in cancer cells enhances their virus sensitivities (5). In addition, a recent study by Shafren et al. (21) indicated that the antiviral activity of plasminogen activator inhibitor type 2 is mediated via the transcriptional downregulation of virus receptors including CAR. It appears that CAR is a key determinant for the virus sensitivity of target cells; therefore, screening the status of CAR in target cells should become a criterion for the patients who are admitted to adenovirus gene therapy. Here we developed a sensitive, quantitative, and rapid assay to determine CAR gene expression using the real-time RT-PCR technique. We demonstrated that CAR mRNA expression correlated with virus binding from a variety of cell lines (Figure 2), and we were able to measure the CAR gene expression in cells treated with HDAC inhibitor (Figure 3). Most importantly, this assay is applicable to tumor specimens (Figure 4).

Moreover, data from Figure 2 clearly indicated that CAR is the principal adenovirus receptor in many cells tested. However, we also noticed that there was some virus binding in cells with no CAR mRNA, suggesting that virus could bind to other protein molecules, such as integrin and heparan sulfate proteoglycan (6-10), on cell surfaces with a very low affinity. However, our data indicated that HDAC could induce endogenous CAR gene transcription in urogenital cancer cells (Figure 3). Thus, we would expect that transcriptional regulation plays a dominant role in CAR expression in cancer cells.

From the experiment using culture cells (Figure 2), we found that the outcome of the results was not significantly different using either the copy number of CAR mRNA or the relative CAR mRNA level as a variable compared with virus binding. However, from the experiment using tumor-tissue samples (Figure 4), we noticed that the outcome had a better statistical significance if the relative CAR mRNA level was used instead of the copy number of CAR mRNA as a variable. It indicated that normalizing target genes with a suitable internal control is necessary to eliminate any possible sampling error that might be due to improper sample preservation or specimens with necrosis.

In summary, we believe that this assay is valuable not only for screening the original status of CAR in patients but also for quantifying changes in CAR levels during virus administration. Such application should help clinicians to adjust both the virus dosage and administration schedules more efficiently, which will certainly reduce adverse toxicity and enhance therapeutic efficacy.

\section{ACKNOWLEDGMENTS}

We thank Richard Hsu for editing this manuscript. This work was sup- ported in part by Gillson Longenbaugh Foundation and National Institutes of Health grant no. CA 95730.

\section{REFERENCES}

1.Freimuth, P. 1996. A human cell line selected for resistance to adenovirus infection has reduced levels of the virus receptor. J. Virol. 70:4081-4085.

2.Zabner, J., P. Freimuth, A. Puga, A. Fabrega, and M.J. Welsh. 1997. Lack of high affinity fiber receptor activity explains the resistance of ciliated airway epithelia to adenovirus infection. J. Clin. Invest. 100:11441149.

3.Bergelson, J.M., J.A. Cunningham, G. Droguett, E.A. Kurt-Jones, A. Krithivas, J.S. Hong, M.S. Horwitz, R.L. Crowell, et al. 1997. Isolation of a common receptor for coxsakie B viruses and adenoviruses 2 and 5 . Science 275:1320-1323.

4.Tomko, R.P., R. Xu, and L. Philipson. 1997. HCAR and MCAR: the human and mouse cellular receptors for subgroup $\mathrm{C}$ adenoviruses and group B coxsakieviruses. Proc. Natl. Acad. Sci. USA 94:3352-3356.

5.Li, Y., R.C. Pong, M.C. Hall, A. Sagalowsky, C.P. Tseng, Z. Wang, J.M. Bergelson, and J.T. Hsieh. 1999. Loss of adenoviral receptor expression in human bladder cancer cells: a potential impact on the efficacy of gene therapy. Cancer Res. 59:325-330.

6.Mathias, P., T. Wickham, M. Moore, and G. Nemerow. 1994. Multiple adenovirus serotypes use $\alpha_{\mathrm{v}}$ integrins for infection. J. Virol. 68:6811-6814.

7.Davison, E., R.M. Diaz, I.R. Hart, G. Santis, and J.F. Marshall. 1997. Integrin $\alpha_{5} \beta_{1}$ mediated adenovirus infection is enhanced by the integrin-activating antibody TS2/16. J. Virol. 71:6204-6207.

8.Wickham, T., J.P. Mathias, D.A. Cheresh, and G.R. Nemerow. 1993. Integrins $\alpha_{v} \beta_{3}$ and $\alpha_{\mathrm{v}} \beta_{5}$ promote adenovirus internalization but not virus attachment. Cell 73:309-319.

9.Dechecchi, M.C., A. Tamanini, A. Bonizzato, and G. Cabrini. 2000. Heparan sulfate glycosaminoglycans are involved in adenovirus type 5 and 2-host cell interactions. Virol. 268:382-390.

10.Dechecchi, M.C., P. Melotti, A. Bonizzato, M. Santacatterina, M. Chilosi, and G. Cabrini. 2001. Heparan sulfate glycosaminoglycans are receptors sufficient to mediate the initial binding of adenovirus types 2 and 5. J. Virol. 75:8772-8780.

11.Okegawa, T., Y. Li, R.C. Pong, J. Zhou, J. Bergelson, and J.T. Hsieh. 2000. The dual impact of coxsackie and adenovirus receptor expression on human prostate cancer gene therapy. Cancer Res. 60:5031-5036.

12.Hemmi, S., R. Geertsen, A. Mezzacasa, I. Peter, and R. Dummer. 1998. The presence of human coxsackievirus and adenovirus receptor is associated with efficient adenovirus-mediated transgene expression in human melanoma cell cultures. Hum. Gene Ther. 9:2363-2373. 
13.Wang, Z., C.P. Tseng, R.C. Pong, H. Chen, J.D. McConnell, N. Navone, and J.T. Hsieh. 2002. The mechanism of growth-inhibitory effect of DOC-2/DAB-2 in prostate cancer. J. Biol. Chem. 277:12622-12631.

14.Hall, M.C., Y. Li, R.C. Pong, B. Ely, A. Sagalowsky, and J.T. Hsieh. 2000. The growth inhibitory effect of p21 adenovirus on human bladder cancer cells. J. Urol. 163:1033-1038

15.Pong, R.C., Y. Li, T. Okegawa, H. Saboorian, G. Lindberg, A. Sagalowsky, and J.T. Hsieh. 2002. Evaluating the expression of the coxsackie and adenovirus receptor (CAR) in patients with bladder cancer. J. Urol. 167:111A.

16.Lee, C.T., J.Y. Seol, K.H. Park, C.G. Yoo, Y.W. Kim, C. Ahn, Y.W. Song, S.K. Han, et al. 2001. Differential effects of adenovirus-p16 on bladder cancer cell lines can be overcome by the addition of butyrate. Clin. Cancer Res. 7:210-214.

17.Kitazono, M., V.K. Rao, R. Robey, T. Aikou, S. Bates, T. Fojo, and M.E. Goldsmith. 2002. Histone deacetylase inhibitor FR901228 enhances adenovirus infection of hematopoietic cells. Blood 99:2248-2251.
18.Kitazono, M., M.E., Goldsmith, T. Aikou, S. Bates, and T. Fojo. 2001. Enhanced adenovirus transgene expression in malignant cells treated with the histone deacetylase inhibitor FR901228. Cancer Res. 61:63286330.

19.Miller, C.R., D.J. Buchsbaum, P.N. Reynolds, J.T. Douglas, G.Y. Gillespie, M.S. Mayo, D. Raben, and D.T. Curiel. 1998. Differential susceptibility of primary and established human glioma cells to adenovirus infection: targeting via the epidermal growth factor receptor achieves fiber receptor-independent gene transfer. Cancer Res. 58:5738-5748

20.Nalbantoglu, J., G. Pari, G. Karpati, and P.C. Holland. 1999. Expression of the primary coxsackie and adenovirus receptor is downregulated during skeletal muscle maturation and limits the efficacy of adenovirusmediated gene delivery to muscle cells. Hum. Gene Ther. 10:1009-1019.

21.Shafren, D.R., J. Gardner, V.H. Mann, T.M. Antalis, and A. Suhrbier. 1999. Picornavirus receptor down-regulation by plasminogen activator inhibitor type 2. J. Virol. 73:7193-7198
Received 5 December 2002; accepted 19 March 2003.

\section{Address correspondence to:}

Jer-Tsong Hsieh

Department of Urology

University of Texas Southwestern Medical Center

5323 Harry Hines Boulevard

Dallas, Texas 75390-9110, USA

e-mail:jt.hsieh@utsouthwestern.edu 